\title{
Bio-inspired design material: a multipurpose case study
}

\author{
T. Alqalami, V. Ahmed \& M. Ormerod \\ School of the Built Environment, University of Salford, UK
}

\begin{abstract}
Demands for new architecture that is more fluid, interactive, functional, and adaptable to the changes of economic atmosphere and design principles are changing the concept of forms and aesthetics. However, despite the role of technology, the architectural design elements of buildings have often been developed separately, in terms of artistic and functional features, in a way that affects the flexibility and quality of the design process along with its impact on the built environment. This issue calls for the need to explore an interdisciplinary design approach that combines biology and architecture in order to improve both individual and overall quality of design.

This paper will, therefore, provide a review of literature that draws on the important characteristics of bio-inspired design material and its impact on an effective design in a way that can capture the specifications needed to enhance the development of a digital prototype that caters for the flexibility and overall quality of design aesthetically and functionally.

Keywords: architecture, nature, biomimetics, mimetics, technology, pattern smart material, quality, aesthetic, functional.
\end{abstract}

\section{Introduction}

Gruber [1] noted that architecture is part of mankind's community and culture as it provides shelter from environmental changes. Accordingly, architects need to develop other ways of design that can adapt to future problems for instance the increasing rates of pollution along with the exploitation of raw materials, extensive use of energy, production of waste and emissions into soil, water, and air. In addition, the effects of global warming along with the escalation of other problems like waste of material and energy use and green-house gas emissions, all these 
issues add to the pressure that the built environment has to face [2, 3]. Equally as importantly, Bruckner [4] argued that the complexity of architecture enables it to adopt elements and buildings of all scales whether it is a nanoscale surface project or an urban design project. Moreover, according to Alexander [5], both nature and architecture have rules that hold their systems together. These rules create a pattern and it is a necessity to observe that pattern as it holds both systems together being part of the ambiance surrounding the built environment. Furthermore, Gruber [6] argues that although nature is alive while architecture is not, both of them are still subjected to the same environmental conditions and physical principles.

This paper focuses on identifying the main characteristics of bio-inspired material design specifications by combining both aesthetic and functional aspects. Such findings will contribute to a future development of a digital prototype which will provide a visual demonstration of such characteristics and their value to the flexibility of design.

\section{Literature review}

\subsection{Nature as a source of inspiration}

The current body of literature overwhelmingly argues that the interactivity of architecture enables it to have an integrated design approach with the surrounding environment combining more than one discipline at the same time. In the same meaning, Oosterhuis [7] noted that architecture is an interacted discipline that is associated with design transactions not just in buildings but life and living systems as well. Consequently, a number of architects have approached nature through their designs such as as Alvar Alto, Frank Lloyd Wright, and Le Corbusier, as described by Gruber [8]. For instance, Porphyrios [9] stated that architects like Aalto have looked at nature for guidance between biology and architecture where the scale of the rooms equals the one of the organic cells. However, this approach has not been new as Leonardo da Vinci stated, "In her [nature's] inventions nothing is lacking, and nothing is superfluous." It is true that nature has always acted sustainably by using minimal resources to achieve maximum performances [10]. Furthermore, Gruber [6] argued that although nature is alive while architecture is not, both of them are still subjected to the same environmental conditions and physical principles.

Therefore, the next section will explore in deep the integrated relationship between architecture and nature in terms of biomimetics inspiration.

\subsection{Biomimetics: definitions and synonyms}

There is little published about architecture's integrated relationship between nature and culture, although studies show that a great deal more investigation is necessary into the ability of architecture to intervene and imitate nature. There are multiple sources for inspirations that designers may use to challenge design problems. One of these is nature: they study its evolving adaptability to environmental changes by a term called biomimetics which was first introduced 
by Otto Schmitt in the 1950s (see $[11,12]$ ). In addition, biomimetics in its multilayered complex system is thought to improve and cater for technological innovation by applying profound scientific principles [13]. The presence of biomimetics in architecture started when there was a necessity for an innovative design approach to have a better design quality that withstands the new environmental issues particularly climate changes, energy and resources, ecology and sustainability [1]. Furthermore, Gebeshuber et al. [14] argued that there is no fine line between material, surface or structure in natural models because they all work as a one entity with the surrounding environment for the service of the model. Similarly, the use of smart material have become very common in building industry because of the ability to react to the changes of the surrounding environment. For example, this issue can be seen in products properties including anti-reflectivity, switchable transparency and darkening in photochromic glass.

However, Bruckner [15] discussed that not all aspects of biomimetics approach could be part of the design process due to lack of clarity in certain outcomes which may not serve aesthetic qualities. In this sense, there are studies that discuss the limitations of both fields. According to Knippers and Speck [16], biological systems are bonded to the same structural elements through their entire life and that in return limit their lifelong performance. Also, Gould and Lewontin [17] mentioned that architecture also has the limitations accompanied to its functional expectations which in return limit the flexibility of its design and construction process. Moreover, Wiscombe [18] argued that, architectural elements have been developed separately in terms of skin and structure.

In brief, Gruber [1] argued that one of the objectives is to bring biomimetics strategies in a way that solves mutual inabilities of both architecture and the built environment for establishing a more appropriate and sustainable design as well. Nevertheless, a complete analytical overlapped approach has not been well established.

This section discusses the importance of biomimetics as part of nature's inspiration source along with its profound scientific relationship with technology in terms of material properties. Therefore, the next section will discuss in deep the relationship between biomimetics and technology.

\subsection{Biomimetics and the role of technology}

There are a number of studies that define biomimetics through its integrated relationship with technology. In this sense, Nachtigall [19], and Vincent et al. [20] stated that the German term bionik has been equal to biomimetics in the English word Bionic which is a combination of two words "Bio" and "mimetics". Nachtigall [19] notes that the word Bionic (Bionik) was reintroduced by US Air Force Major J.E. Steele at a conference entitled "Bionic symposium: living prototypes - the key to new technology" in 1960. The bionic approach is defined as an independent information transfer between biology and technology using an integrated perspective inspired by nature with the aid of technological implementation where technology has an obligation towards knowledge through illustrating part of the unknown into an interactive biological and technical 
methods and strategies. As for the mimetics part, Gruber [1] argued that it is concerned with mimicking nature's models which is still a controversial one.

Biomimetics, in particular, applies that in a way by using the technological tools (non-living systems) to interpret biological modals (living systems) in nature. Nevertheless, the word bio-inspiration has been used more instead of bionic yet still seen in a more general perspective that does not have the defined background which outlines the specific strategies and methods necessary for the design process.

This section identifies the impact of technology as part of the interpretation process between biological models and architecture. Therefore the next section remarks the essence of architecture and its interactive relationship with quality in terms of material.

\subsection{Architecture: essence and quality in terms of material}

According to Bayer (1992, cited in [21]), the identity of an architectural object lies in its material. Furthermore, Frankl [22] argued that architecture has an essence that is expressed through material which in return related to its function. In this sense, Aristotle [23] stated that essence equals the quality as it is derived from the Latin essentia as the stem esse, and the Greek ousia. Another important word in the creation of a building is whole. Vitruvius [24] demonstrated that the parts should be guided by the harmony and equally designed relationships in order to create the frame of the whole structure. However, Johnson [25] discussed that the word wholeness did not appear to have a critical existence in the art and architecture of ancient Greek. Instead there was always the mention of quality that embodies the work of art and architecture. Likewise, Ruskin [26] argued that it is important to have a complete perspective that deals collectively with the whole parts together. Furthermore, there is no ideal perspective that caters only for one part of the entire building.

Similarly, according to Gruber [1], natural models go through complicated transformations that are not only related to the form but to the function as well. In this sense, biomimetics as an approach in architecture or any other discipline is not about coping what nature has in common with architecture. On the contrary, it is about adapting the deep qualities of nature whether in terms of material, construction, transformation process, or function.

This section notes that both quality and essence of architecture can be expressed in a material that takes into consideration the building as a whole within the relationship of form and function. Therefore, the next section discusses in deep the relationship between aesthetic and functional aspects in relation to design quality.

\subsection{Functional beauty}

This section discusses the layers of architecture that discuss the integrated relationship between aesthetic and functional design aspects.

The essence of architecture is found in whatever buildings exist. Equally importantly, Aristotle et al. [27] stated that any change if it doesn't add to the essence of the object then it will be useless for the purpose it is made for. For 
example, the theory of organic form was not about the apparent shape but it was all about the function of that form [28]. Nevertheless, Steadman [29] argued that the term organic architecture is more about the aesthetic appreciation. In other words organic architecture combines the work of art and the phenomena of nature. Equally relevantly, aesthetic properties could appear from a background of a nonaesthetic ones $[30,31]$. In the same meaning, non-aesthetic categories could be perceived as beauty for its functional needs [32-35].

However, such relationship between aesthetic and function has not been explored as a whole within the principles of architectural design process. This claim could be achieved within the quality of design elements in terms of shapes, colours, lines, and so on [36]. Thus, the next section will discuss the importance of understanding the pattern and its layers as part of the creative design process in nature and architecture.

\subsection{The presence of patterns in design}

Having identified the essence of design and the importance of combining the aesthetic and non-aesthetic aspects of design, this section builds on the concepts by introducing the importance of understanding the idea of pattern. According to Thompson [37], the pattern is the identity of any object whether in nature or architecture. Within its layers, pattern can identify all the details needed to comprehend its transitions and changes from inside out. Moreover, according to Wurman, cited by Garcia [38], as an information architect and designer, he noted that as the world is a mixed series of visual patterns, there is no chance for the emergence of any creative process without fully understanding the parts of these patterns. Moreover, architecture is in the middle between nature and manmade world [39]. Moreover, Ball [40] an influential science writer, argued that a large number of distinctive patterns is manmade pattern formed by human intelligence and functional needs.

Therefore, the next section will discuss the importance of maintaining a clear interpretation process of information transfer between biological models and architecture by understanding the pattern of each.

\subsection{Application of bio-inspired design pattern as part of biomimetics strategies}

One of the approaches is where designers look for biomimetics strategies in order to employ their solutions within the design process in an attempt to solve design problems through specific goals and parameters based on biologists' perspective [41]. For example, according to Wiscombe [18], a growing desire to have a sustainable built environment has developed an innovative architectural design based on an overlap between biological and architectural where the surface is not just an abstract but also a mix between embedded technology and design elements, between quality and sensation, function and form. According to Gruber and Jeronimidis [42], Tom Wiscombe's [43] visionary design tackle two important parts. One is about different strategies applied to the surface such as de-lamination, blending, embedding, fusing, and winding in order to convey the design elements. 
The other one is the functional requirements of bioinspired material principles. These two, if applicable, could create the assets of future built environments. For instance, an Australian Agamid lizard is known for its interwoven skin features. In addition to its skin display of colour variation, the grooves on the skin play an intensive part for their survival through the conduction of water from lizard's back into its mouth. In architectural design, a project for EMERGENT lizard panel facade, 2009 is a prototype inspires from biomimetics strategy through the transparent facade with embedded interwoven systems of a grey water capture system and an algae photo-bioreactor system in a way that produces structural as well as ornamental effects, as shown in fig. 1 [43].
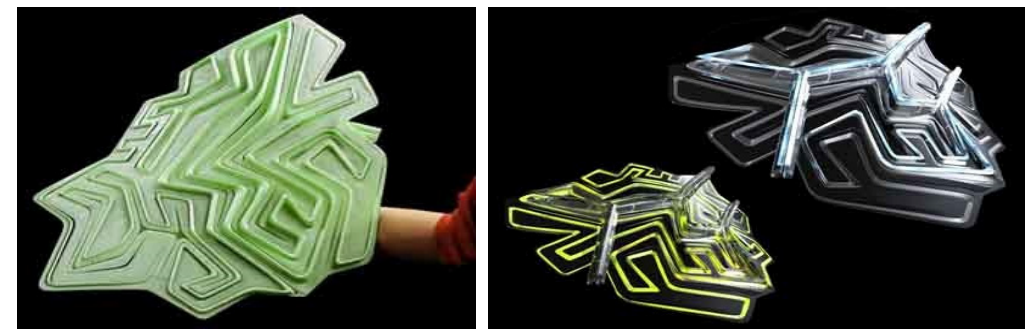

Figure 1: EMERGENT prototype for lizard panel facade, 2009 [43].

In this sense, according to Wiscombe [18], an overlap between architecture and other disciplines will help to change the fixed functional and aesthetic standards. The aim is to come up with an approach that would surpasses zero element thickness into a multifunctional embedded technology within architectural surface to maintain a constant information transfer between structure and envelope. This could be achieved through composite design patterns with a transformation from a 2-dimensional into a 3-dimensional surface.

Notwithstanding, according to Kua and Lee [44], although there have been new technologies developed in terms of new material and fundamental systems, still the construction industry is slow in the uptake of these technologies. This phenomenon is quite common, and normally it takes 10-20 years before such technologies are adapted by the industry due to the resistance to take risks by the developers and property owners as well.

This section identifies that an interdisciplinary approach between biology and architecture will change the fixed standards into a combined aesthetic and functional aspect through a multifunctional embedded technology. Thus, the next section will discuss the impact of technological advancement on the quality and flexibility of design in terms of material design specifications.

\subsection{Integrated applications between technology and biological phenomenon in design: modern material and the development of technology}

According to Pallasmaa [39], although old materials tend to present and preserve the origin and history attached to it, yet the goal of technological advancement has taken architectural imagination towards ageless perfection accompanied with 
layers that utilise reflection, gradations of transparency and weightless measures. Nevertheless, the construction standards are still trapped within the constraints of natural material like stone, brick, and wood.

Equally as importantly, one of the less energy efficient building component with a larger maintenance requirements are windows. Nevertheless, due the technology improves the quality of design by improving the standards of windows production. For instance, smart windows can change properties like the solar factor in response to the changing of environmental conditions. Hence, a transparent mode of the glazing window has to be possible [45].

Notwithstanding, the progress of smart glass has been really slow although it has been discovered and made publicly in the 1970s and the 1980s. The smart windows were not acknowledged until the need for alternative solutions to control daylight and solar energy in buildings [45]. For example, the "SPD" suspended particle device technology. This material is based on layers starting from two glass or transparent plastic surfaces with special conductivity coatings on the panel interior. The use of this material gives the facility owner the possibility to use it at their own discretion, as shown in fig. 2. Such potentials are made when power in the SPD partition panel is on in the conductive layers, the temporarily suspended particles in the layer are oriented in the electrical field and allow the passage of light through the panel. Sensor-controlled voltage can assume infinite number of shades of transparency up to full opacity. The space users have the ability to render the panel fully opaque in a moment (change time is $1 \mathrm{sec}$.) and return of full clarity comes after 3 seconds [46].
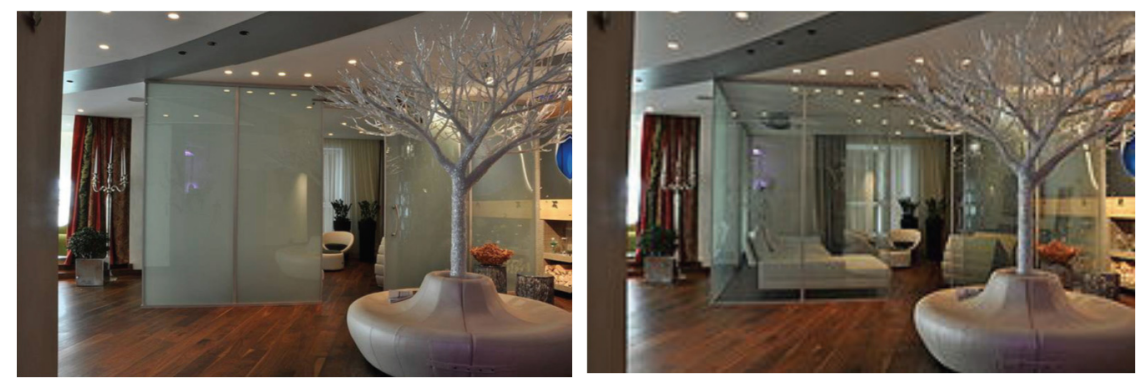

Figure 2: The left image illustrates the discretion of the smart panel, while the image on the right demonstrates the same partition but in its full transparent state, as a result of on and off programming option times of transparency and opacity phases [46].

There is no need for the use of electricity in the dimmed state. Moreover, the power consumption in operation is very small and the process of on and off cycles is virtually unlimited. This process provides multiple options in the way of room lighting and the manner of its use. According to Gavrilović Dragan and Stojić [47], the use of new smart panels provides a flexibility in design by combining both aesthetic and functional aspects. The aesthetic aspects are demonstrated through the use of not just glass but transparent plastic surfaces as well which gives the 
ability to design curved surfaces to be used for multifunctional areas. Also, the use of such material improves the quality of functional aspects in architecture of commercial and residential building by reducing the overall energy consumption and achieving better energy benefits. In addition, smart glass can be used as a smart wall in contemporary architecture and as a smart window as well.

\section{Methodological approach}

This paper is part of an ongoing $\mathrm{PhD}$ study that is conducted in four stages:

Stage I: This stage is focused on understanding the qualities of aesthetic and functional characteristics of biomimetic materials and identifying the main factors that would affect both the individual and overall quality of material design specifications.

Stage II: This stage entails qualitative data collection in order to identify the layers of an integrated architectural design pattern that combines both aesthetic and functional aspects.

Stage III: This stage entails the development of an interface which caters for the quality and flexibility of design as well as the sustainability of the built environment.

Stage IV: This stage entails the evaluation of the interface.

This paper only focuses on the first stage of the research by identifying the characteristic of the bio-inspired design material.

\section{Main findings}

This section gives an overview of the results obtained from the literature review as follows:

1. Understanding the pattern and its layers whether in nature or architecture is important to improve the quality of an interdisciplinary design approach.

2. The multi-layered complex system of biomimetics enables it to have a profound scientific relationship with multifunctional embedded technology as part of the mimicking in the interpretation process between living systems in nature and non-living systems of architecture in terms of material.

3. In natural models, material equals to both surface and structure as one entity in serving the model against the changes of the surrounding environment.

4. Material in natural models equals smart material in its ability to adapt to the changes of the surrounding environment: a) Smart materials can be made of glass or plastic to be used as a wall or window. b) Using plastic gives the opportunity to create different shapes and curves. c) Smart material can be translucent with the possibility to change the opacity from opaque to transparent for multipurpose use between public to private space needs. d) It has less energy consumption.

5. Design strategies such as de-lamination, blending, embedding, fusing, and winding are used in order to convey combined aesthetic and functional aspects within design element in terms of material. 
Such characteristics will contribute to the development of a digital prototype that will integrate these characteristics within a 3D model. The model will enable the end users to explore the combined aesthetic and functional design aspects which will optimize the sustainable features of the design.

\section{Conclusion and future work}

Reviewing the literature showed that both biomimetics and sustainable developments are important in the interpretation process of the information transfer between biological and man-made material specifications. In addition, technology plays an important role in the implementation of biomimetics innovation in design process. The characteristics of bio-inspired material design specifications will be delivered in a multi-layered design element with an integrated relationship between visible and embedded technological systems. For instance, smart glass in SPD depends on layers starting from two glass or transparent plastic surfaces with special conductivity coatings on the panel interior. Such characteristics will visualize the main features of a digital prototype that improves the quality and flexibility of design as well as the sustainability of the built environment.

\section{References}

[1] Gruber, P., Biomimetics in architecture: architecture of life and buildings. 2011, Wien: Springer.

[2] Mazria, E., It's the architecture, stupid! World and I, 2003. 18(10): p. 138145.

[3] Doughty, M.R. and G.P. Hammond, Sustainability and the built environment at and beyond the city scale. Building and Environment, 2004. 39(10): p. 1223-1233.

[4] Bruckner, D., ed. Biomimetics - materials, structures and processes: examples, ideas and case studies. 2011, Springer: London.

[5] Alexander, C., Book two: The process of creating life. Vol. 10. 2002, Berkeley, CA: Center for Environmental Structure.

[6] Gruber, P., Biomimetics in Architecture [Architekturbionik] - the architecture of life and buildings. 2008, Doctoral thesis, Vienna University of Technology.

[7] Oosterhuis, K., Hyperbodies. 2003, Berlin: Springer.

[8] Gruber, P., Biomimetics in Architecture [Architekturbionik], in Biomimetics - Materials, Structures and Processes: Examples, Ideas and Case Studies, P. Gruber, et al., Editors. 2011, Springer: Heidelber. p. 128.

[9] Porphyrios, D., Sources of modern eclecticism: studies on Alvar Aalto. 1982: Academy.

[10] Oxman, N., Structuring materiality design fabrication of heterogeneous materials. Architectural Design, 2010(206): pp. 78-85. 
[11] Bar-Cohen, Y. Biomimetics: mimicking and inspired-by biology in Smart Structures and Materials. 2005. International Society for Optics and Photonics.

[12] Vincent, J., et al., Biomimetics: its practice and theory. Journal of the Royal Society, Interface/the Royal Society, 2006, 3(9): p. 471.

[13] Bruckner, D., Biomimetics: Its Technological and Societal Potential, in Biomimetics - Materials, Structures and Processes Examples, Ideas and Case Studies, H. Stachelberger, P. Gruber, and I.C. Gebeshuber, Editors. 2011, Springer: Berlin, p. 2.

[14] Gebeshuber, I.C., et al., Bacilli, green algae, diatoms and red blood cellshow nanobiotechnological research inspires architecture, in Bio-Inspired Nanomaterials and Nanotechnology, Y. Zhou, Editor. 2010, Nova Science. pp. 207-244.

[15] Bruckner, D., Biomorphism in Architecture: Speculations on Growth and form in Biomimetics - Materials, Structures and Processes Examples, Ideas and Case Studies, P. Gruber, et al. (editors). 2011, Springer: Berlin

[16] Knippers, J. and T. Speck, Design and construction principles in nature and architecture. Bioinspiration and Biomimetics, 2012, 7(1): p. 1.

[17] Gould, S.J. and R.C. Lewontin, The spandrels of San Marco and the Panglossian paradigm: a critique of the adaptationist programme. Proceedings of the Royal Society of London. Series B. Biological Sciences, 1979, 205(1161): pp. 581-598.

[18] Wiscombe, T., Beyond assemblies: system convergence and multimateriality. Bioinspiration \& Biomimetics, 2012. 7(1).

[19] Nachtigall, W., Bionik: Grundlagen und Beispiele für Ingenieure und Naturwissenschaftler. 2002, Berlin: Springer Verlag.

[20] Vincent, J.F.V., et al., Biomimetics: its practice and theory. Journal of the Royal Society, Interface/the Royal Society, 2006. 3(9): p. 471.

[21] Lincourt, M., In search of elegance: towards an architecture of satisfaction. 1999, Liverpool: Liverpool University Press.

[22] Frankl, P., Principles of architectural history: the four phases of architectural style, pp. 1420-1900. 1968: MIT Press.

[23] Aristotle, b., Metaphysics. 2004: Digireads.com Publishing.

[24] Vitruvius, The ten books on architecture, ed. M.H. Morgan. 1960, New York: Dover.

[25] Johnson, P.-A., The theory of architecture: concepts, themes \&amp; practices. 1994, New York: John Wiley.

[26] Ruskin, J., Sesame and lilies: The two paths, The King of the Golden River; introduced by Sir Oliver Lodge. 1907, London: Dent.

[27] Aristotle, D.M. Balme, and A. Gotthelf, Aristotle's De Partibus Animalium I: And, De Generatione Animalium I (with Passages from II. 1-3). 1972, Cambridge: Cambridge University Press.

[28] Bruckner, D., Biomorphism in Architecture: Speculations on Growth and For, in Biomimetics - Materials, Structures and Processes Examples, Ideas and Case Studies, D.B. P. Gruber, C. Hellmich, H.-B. Schmiedmayer, 
H.Stachelberger, I.C. Gebeshuber, Editor. 2011, Berlin; London: Springer Berlin; London, p. 149.

[29] Steadman, P., The evolution of designs. Biological analogy in, 1979.

[30] Sibley, F., Aesthetic concepts. The Philosophical Review, 1959: pp. 421450.

[31] Cohen, T., Aesthetic/Non-aesthetic and the concept of taste: a critique of Sibley's position. Theoria, 1973. 39(1-3): pp. 113-152.

[32] Davies, S., Aesthetic judgements, artworks and functional beauty. Philos. Q., 2006. 56(223): pp. 224-241.

[33] Shiner, L., On Aesthetics and Function in Architecture: The Case of the "Spectacle" Art Museum. J. Aesthet. Art Crit., 2011. 69(1): pp. 31-41.

[34] Parsons, G., Functional Beauty. Vol. 67. 2008, Oxford: Oxford University Press, pp. 341-343.

[35] Functional Beauty. British journal of aesthetics, 2010. 50(2): pp. 215-219.

[36] Sauchelli, A., Functional beauty, architecture, and morality: A beautiful Konzentrationslager? Philosophical Quarterly 2012. 62(246): p. 130.

[37] Thompson, D.W., On growth and form. On growth and form, 1942.

[38] Garcia, M., Prologue for a History, Theory and Future of Patterns of Architecture and Spatial Design. Architectural Design, 2009. 79(6): pp. 617.

[39] Pallasmaa, J., The eyes of the skin: architecture and the senses. 2012, Chichester: Wiley.

[40] Ball, P., Nature's patterns: a tapestry in three parts. Shapes. 2009, Oxford: Oxford University Press.

[41] Zari, M.P. Biomimetic approaches to architectural design for increased sustainability in The SB07 NZ Sustainable Building Conference, Auckland, New Zealand. Retrieved February. 2007.

[42] Gruber, P. and G. Jeronimidis, Has biomimetics arrived in architecture? Bioinspiration \& Biomimetics, 2012. 7(1).

[43] Wiscombe, T., Extreme integration. Architectural Design, 2010(204): pp. 78-87.

[44] Kua, H.W. and S.E. Lee, Demonstration intelligent building - a methodology for the promotion of total sustainability in the built environment. Building and Environment, 2002. 37(3): pp. 231-240.

[45] Baetens, R., B.P. Jelle, and A. Gustavsen, Properties, requirements and possibilities of smart windows for dynamic daylight and solar energy control in buildings: A state-of-the-art review. Solar Energy Materials and Solar Cells, 2010. 94(2): pp. 87-105.

[46] Gavrilović, D.J. and J. Stojić, Usage of "Smart" Glass Panels In Commercial and Residential Buildings. Facta Universitatis Series: Architecture and Civil Engineering, 2011. 9(2): p. 261.

[47] Gavrilović Dragan, J. and J. Stojić, Usage of "smart" glass panels in commercial and residential buildings. Facta Universitatis Series: Architecture and Civil Engineering, 2011. 9(2): p. 261. 